\title{
Effect of Soil Burial on Tensile Properties of Polypropylene/Plasticized Cassava Starch Blends
}

\author{
Henry C. Obasi, Isaac O. Igwe, and Innocent C. Madufor \\ Department of Polymer and Tensile Engineering, Federal University of Technology, Owerri, Imo State 1526, Nigeria \\ Correspondence should be addressed to Henry C. Obasi; neduobasi35@yahoo.com
}

Received 31 May 2013; Revised 26 September 2013; Accepted 26 September 2013

Academic Editor: Jun Zhang

Copyright ( 2013 Henry C. Obasi et al. This is an open access article distributed under the Creative Commons Attribution License, which permits unrestricted use, distribution, and reproduction in any medium, provided the original work is properly cited.

Polypropylene (PP)/plasticized cassava starch (PCS) blended with and without compatibilizer (polypropylene-graft-maleic anhydride (PP-g-MA)) via melt blending were prepared for soil burial which lasted for 90 days. Plasticized starch loadings of $0,10,20,30,40$, and $50 \mathrm{wt} . \%$ were used, while pp-g-ma was used at $10 \mathrm{wt} . \%$ based on starch weight. The PP/PCS and PP/PCS/PPG-MA blends were evaluated for their tensile properties. It was observed that the tensile strength, elongation at break, and young's modulus decreased with increases in soil burial time as well as starch content for PP/PCS blends. Similar treads for the tensile properties were observed for PP/PCS/PP-g-MA, but with higher properties as compared to uncompatibilized blends. However, the tensile properties for both PP/PCS and PP/PCS/PP-g-Ma decrease with increases in starch loading and also as the burial period progressed.

\section{Introduction}

Throughout the world, over 120 million tons of plastics are being utilized annually. The plastics industry has worked tremendously on the synthesis, formulation, and utilization of durable materials that are more adapted to their specific uses. Among these applications, over 30 million tons of these plastics are used for packaging purposes such as waste bags, agricultural mulch films or continually [1]. However, despite many great benefits, these polymers are considered to be resistant to microbial attack. This gives rise to serious environmental problems. Landfills are occupied by plastic waste [2]. Polypropylene (PP), a polyolefin, has a major part in the market force. It has many usages in the production of films packaging, sutures, injection, and rotational molding. In general, the use of polyolefin has been limited due to its nondegradable nature. Most countries are working on reducing the amount of plastics waste by means of recycling, but this has proved to be unsuitable and uneconomical for certain end-use applications [3].

Plastics can be modified with ease by addition of a variety of additives and fillers to give desired end-use products.
Development of biodegradable plastics is considered as the best approach to solve solid waste problems. This awareness gave rise to an interest in the development of polymers that will fragment or degrade into benign by-products under composting environments [3]. Blending synthetic polymers with natural polymers such as starch, cellulose, lignin, chitin and chitosan is applied as an important way to accelerate polymer degradation $[4,5]$.

The use of renewable botanical resources such as starch is considered a cheap way of developing biodegradable materials [3]. Biodegradation ocean when microorganisms such as bacteria or fungi consume plastics in an aerobic or anaerobic environment gives out carbon dioxide, methane, and other natural products [6]. The limitation associated with the use of starch in polymer is its hydrophilic nature and the generally hydrophobic nature of the polymer matrix.

Thermoplastic starch (TPS) is obtained by gelatinization of starch in the presence of suitable plasticizers such as water or glycerol [7]. It is a translucent amorphous material that looks and feels much like conventional plastics. The TPS can be shaped into pellets, injection molded into articles, and biodegraded quickly. Its properties and dimensional stability 
are influenced by moisture. Physical and processing properties of thermoplastic starch can be improved by blending it with synthetic polymers.

Polypropylene/plasticized cassava starch blends were subjected to soil burial in their study. The objective of study is to investigate the behavior of the samples after soil burial environment and the effects of plasticizer and the addition of PP-g-MA. The tensile test was applied to determine the changes of tensile properties after the soil burial test. The difference between the compatibilized plasticized and plasticized blends was also discussed in this study.

\section{Experiment}

2.1. Materials. Cassava starch was extracted from cassava roofs obtained from the eastern part of Nigeria according to the method adopted by Integrated Cassava Project (ICP) of the Federal Ministry of Agricultural and Rural Development, Nigeria. It has a particle size of $0.075 \mathrm{~mm}$.

Pellets of polypropylene (PP) with melting temperature of $165^{\circ} \mathrm{C}$ and MFI of $70 \mathrm{~g} / 10 \mathrm{~min}$ were obtained from CeePlast Nig. Ltd.

Maleic anhydride-graft-polypropylene (MA-g-PP) was obtained from Sigma-Aldrich Corporation with melting point of $156^{\circ} \mathrm{C}$ and density of $0.934 \mathrm{~g} / \mathrm{cm}^{3}$. Glycerol was obtained from Ajax Chemicals. Both MA-g-PP and glycerol were used as obtained.

2.2. Preparations of Plasticized Cassava Starch. Plasticized cassava starch (PCS) was prepared from cassava starch using a high speed laboratory mixer according to the method of St-Pierre et al. [8]. Mixing conditions of starch, water, and glycerol was at $70^{\circ} \mathrm{C}$ and $50 \mathrm{rpm}$. The PCS obtained was oven dried at $90^{\circ} \mathrm{C}$ for $12 \mathrm{~h}$ to reduce its moisture content (MC) to about $1 \%$.

2.3. Polypropylene/PCS Blends Preparation. Compounds of polypropylene with plasticized cassava starch (PCS) were melt-blended in an injection machine at a temperature of $60-190^{\circ} \mathrm{C}$ and a screw speed of $50 \mathrm{rpm}$ to obtain PP/PCS composites. The PCS content was $0,10,20,30,40$, and 50 wt. $\%$ in the blends. Maleic anhydride-graft-polypropylene (mAg-PP) was used as a compatibilizer at $10 \mathrm{wt} . \%$ based on the cassava starch content. The liquid melt was injected into a mould to obtain sample sheets. These sheets were oven dried for $24 \mathrm{~h}$ at $70^{\circ} \mathrm{C}$ to avoid moisture infiltration and then stored in a desiccator.

2.4. Soil Burial Test. Soil burial test was carried out on a laboratory scale to examine the biodegradability of the PP/cassava starch blends. Dumbbell shaped specimens of definite sizes were cut from each of the blends. The soil burial test lasted for 90 days. Wet alluvial soil was placed into plastic containers with tiny holes perforated at the bottom and on the side of the container to increase air and water circulation. The soil was kept moist with water and stored outside the room throughout the test period. Dumbbell shaped specimens were buried in the soil at a depth of $10 \mathrm{~cm}$ from the surface and

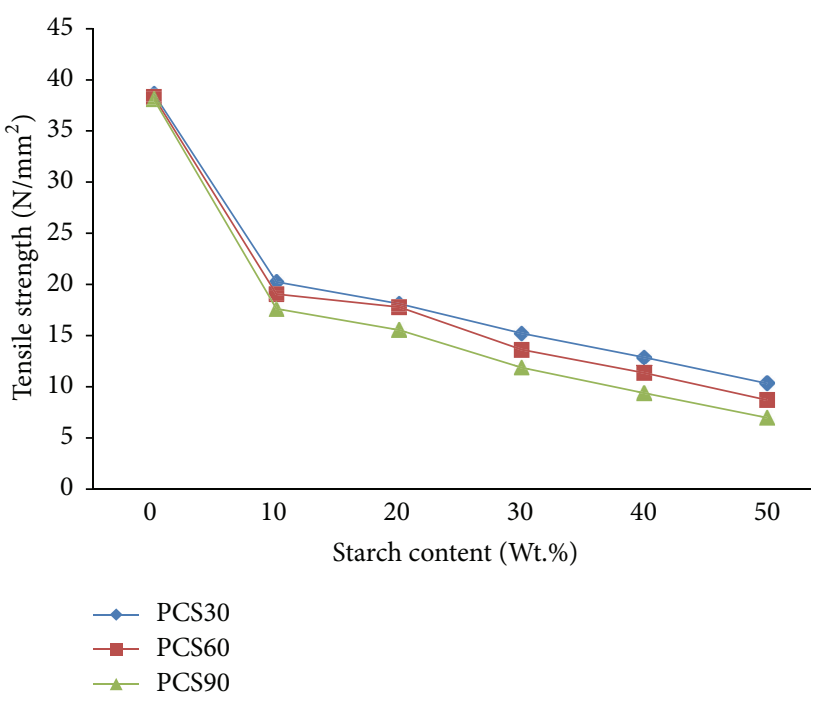

FIGURE 1: Tensile strength of PP/PCS blends after the soil burial test.

thus subjected to the action of microorganisms which are normally present in the soil. After the test, the blend samples were removed, washed with distilled water, dried in the oven at $70^{\circ} \mathrm{C}$ for $24 \mathrm{~h}$, and then kept in a desiccator.

2.5. Tensile Properties. Tensile tests for the exposed samples were carried out with a universal testing machine Instron 3366, according to ASTM D638. Dumbbell shaped specimens of $3 \mathrm{~mm}$ thickness were cut from the moulded samples. The test was performed at a cross head speed of $5 \mathrm{~mm} / \mathrm{min}$ at $25 \pm$ $3^{\circ} \mathrm{C}$. Fine specimens were used to obtain the average values for tensile strength, elongated at break and Young's modulus.

\section{Results and Discussion}

3.1. Tensile Properties. The addition of natural fillers into synthetic polymers will result in blends with adequate properties only when a set of factors are reasonably controlled in their manufacture, such as moisture and particle size which may adversely affect blend properties. Reduction in the tensile strength and elongation at break of the resulting polymer blends is reported as an undesirable effect of the addition of starch to polymers.

Improvement on the flexibility of the blends, strong intermolecular interactions between starch molecules and matrix of the polymer can be achieved with the addition of glycerol to the starch so that starch can be plasticized resulting in less brittle and more homogenous mixture with polypropylene matrix. Figures 1, 2, 3, 4, 5, and 6 show the tensile properties of plasticized blends of PP/CS with and without compatibilizer that were exposed to simple soil environment for the periods of 30,60 , and 90 days.

It can be seen from the figures that the tensile strength, elongation at break, and Young's modulus decreased with the increase in the starch loading and burying time. The decrease in these properties with time of burial was due to the pits and voids which took place after the absorption of the starch 


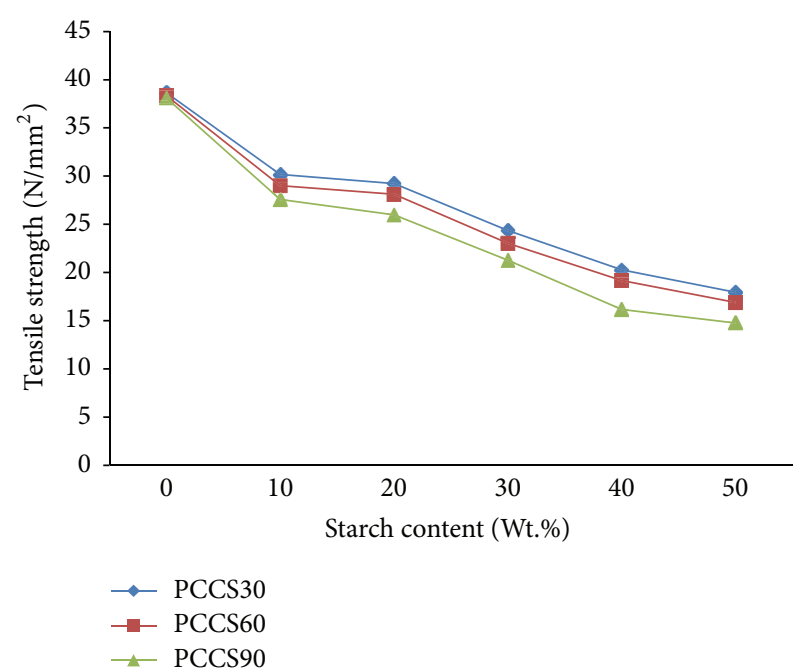

FIgure 2: Tensile strength of PP/PCCS blends after the soil burial test.

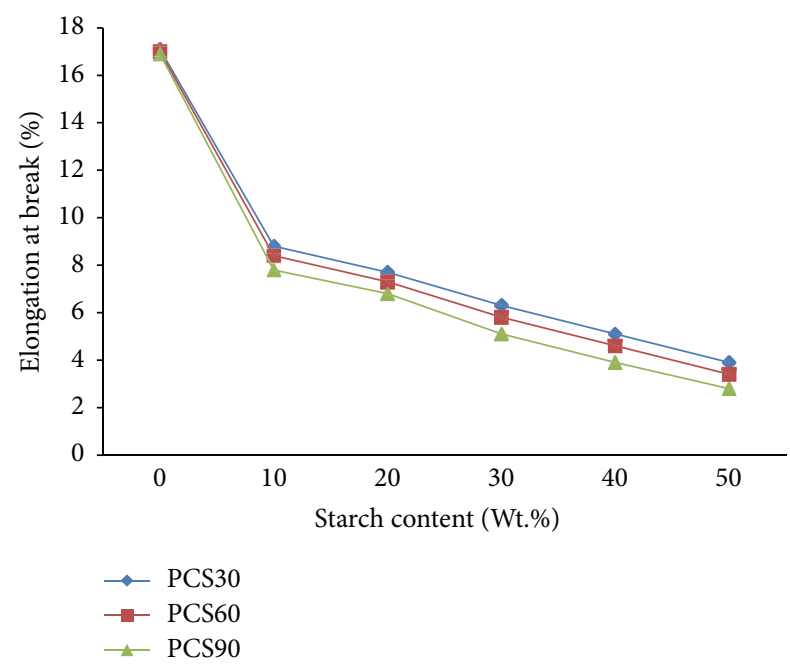

FIGURE 3: Elongation at break of PP/PCS blends after the soil burial test.

particles on the surface of the PP/CS blends. The pit and voids act as stress concentrator and lead to a decrease in tensile strength and Young's modulus [9]. It has been reported that if the starch level exceeds $41 \%$ by weight, continuous biodegradation could take place leaving behind a disintegrated polymer matrix [10].

Furthermore, microorganisms feed on the blends starting with the cassava particles thus resulting in the loss of their structural characteristics. The degradation of the blends occurs due to the quitting of starch sites, which are occupied by either microbes or water. The water absorbed by the blends during the experiment as expected caused swelling of the blends and thus accelerated biodegradation. Starch is a complex polymeric material consisting of amylose and amylopectin. The major constituents of starch can be degraded by many bacteria and fungi in the soil environment.

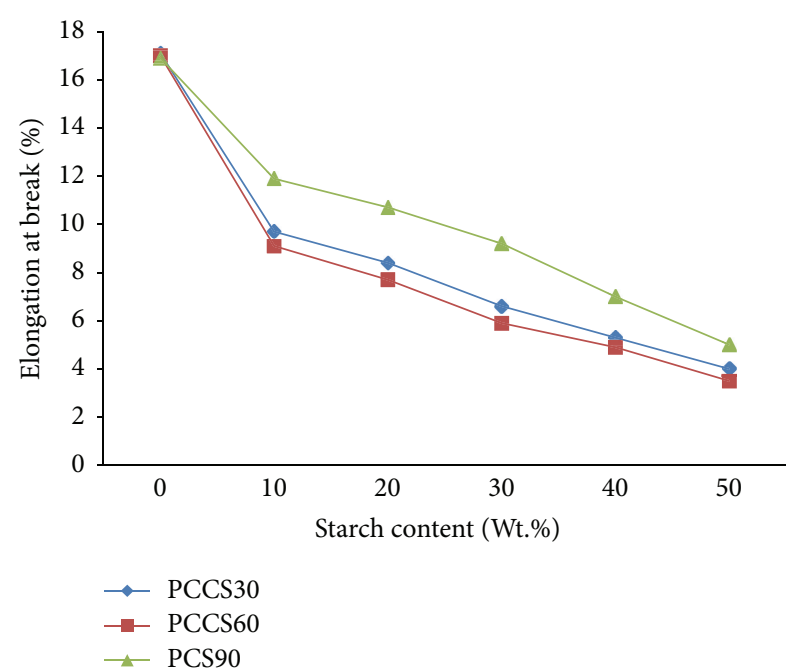

FIGURE 4: Elongation at break of PP/PCCS blends after the soil burial test.

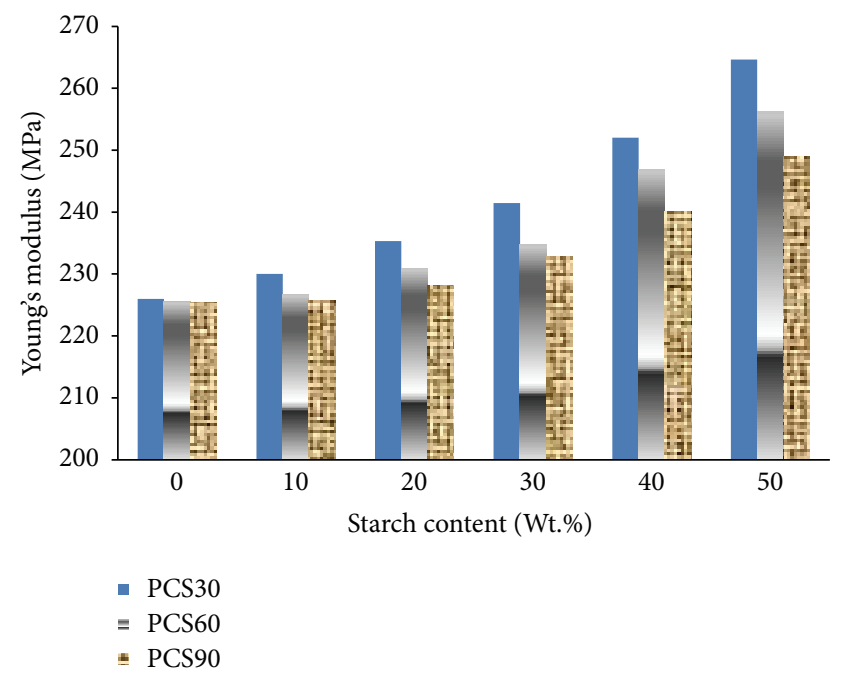

FIGURE 5: Young's modulus of PP/PCS blends after the soil burial test.

Microorganisms can attack the carbohydrate polymers and have very specific enzymes capable of hydrolyzing these polymers into digestible units so that starch structure is weakened and starch strength is reduced.

The blends having higher percentages of starch $(40 \%$ and $50 \%)$ content are expected to degrade faster as compared to the blends with lower starch loading in the first 30 days, during which the maximum starch content was accessed. A progressive decrease of cassava starch was noticed over the next 30 days, and a gradual decrease was observed during the last 30 days as shown in the figures. After 90 days of exposure, compatibilized blend samples showed better resistance with the tensile strength than the uncompatibilized blends. It was also observed that increasing the starch content of the blends could cause the percent degradation of tensile strength to become higher. This condition could be clearly seen for both 
TABLE 1: Percent decrease in tensile strength of PP/PCS after biodegradation.

\begin{tabular}{lccc}
\hline $\begin{array}{l}\text { Starch contents } \\
\text { (Wt.\%) }\end{array}$ & $\begin{array}{c}\text { \% loss in tensile strength } \\
\text { after } 30 \text { days }\end{array}$ & $\begin{array}{c}\text { \% loss in tensile strength } \\
\text { after } 60 \text { days }\end{array}$ & $\begin{array}{c}\text { \% loss in tensile strength } \\
\text { after } 90 \text { days }\end{array}$ \\
\hline 0 & 0.66 & 1.44 & 2.05 \\
10 & 11.24 & 16.88 & 25.77 \\
20 & 13.09 & 14.71 & 29.43 \\
30 & 12.45 & 18.96 & 31.16 \\
40 & 15.45 & 16.65 & 30.14 \\
50 & 16.17 & 20.88 & 40.66 \\
\hline
\end{tabular}

TABlE 2: Percent decrease in tensile strength of PP/PCCS after biodegradation.

\begin{tabular}{lccc}
\hline $\begin{array}{l}\text { Starch contents } \\
(\text { Wt.\%) }\end{array}$ & $\begin{array}{c}\text { \% loss in tensile strength } \\
\text { after 30 days }\end{array}$ & $\begin{array}{c}\text { \% loss in tensile strength } \\
\text { after 60 days }\end{array}$ & $\begin{array}{c}\text { \% loss in tensile strength } \\
\text { after } 90 \text { days }\end{array}$ \\
\hline 0 & 0.66 & 1.44 & 2.05 \\
10 & 5.80 & 9.42 & 21.16 \\
20 & 6.44 & 11.95 & 18.67 \\
30 & 7.77 & 13.64 & 22.08 \\
40 & 9.01 & 8.87 & 18.26 \\
50 & 11.69 & 17.84 & 20.23 \\
\hline
\end{tabular}

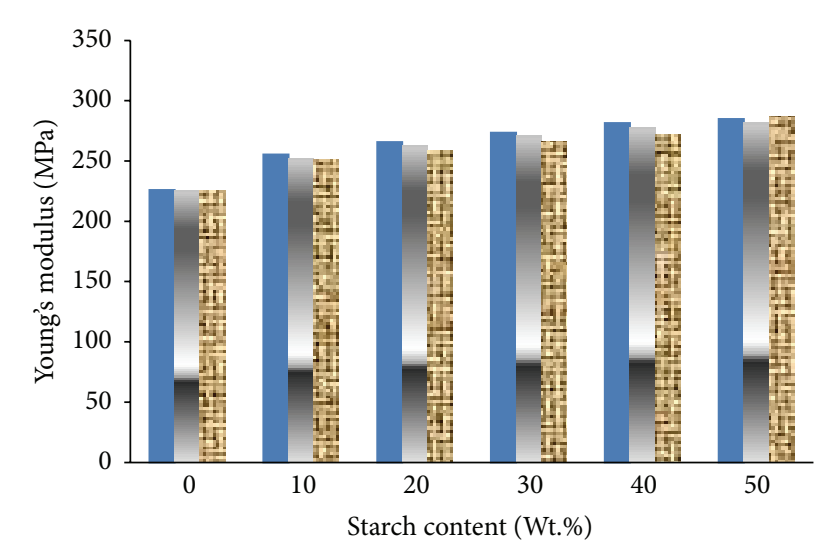

PCCS30
= PCCS60
— PCCS90

FIGURE 6: Young's modulus of PP/PCCS blends after the soil burial test.

types of blends. With the increment of starch content to $50 \mathrm{wt} . \%$, the blends within the 90-day test showed deterioration of $16.17 \%, 20.88 \%$, and $40.66 \%$ for PP/PCS blends in the order of 30,60 , and 90 days of the corresponding initial strength levels, respectively.

Elongation at break exhibited the highest deterioration at the $50 \mathrm{wt} . \%$ starch content of PP/PCS blends (Figures 3 and 4). The percent degradation after 90 days at $50 \mathrm{wt} . \%$ for PP/PCS blends was $23.08 \%, 41.18 \%, 71.43 \%, 17.50 \%, 32.34 \%$, and $58.69 \%$ for PP/PCCS blends in the order 30,60 , and 90 days, respectively. This shows that increasing the starch content in the blends promoted degradation.
As expected, Young's modulus of PP/PCS blends exhibited a similar trend of strength deterioration. The Young's modulus of blends with $50 \mathrm{wt} . \%$ starch content showed a decrease of $2.89 \%, 4.23 \%$, and $5.59 \%$ for PP/PCS blends and $5.02 \%, 8.49 \%$, and $11.60 \%$ for PP/PCCS blends at 30,60 , and 90 days of soil burial, respectively. The percent decrease in degradation was found to be lower for PP/PCCS blends than PP/PCS blends. The presence of compatibilizer with better adhesion between PP matrix and starch filler could act as a protective covering to the action of soil microorganisms.

The percentage decrease in tensile strength for the polypropylene plasticized cassava starch (PP/PCS) and Plasticized compatibilized cassava starch PP/PCCS blends after soil burial for 30,60 , and 90 days was taken as percent loss in tensile strength of the blends when compared with the unburied blends. From the tables, it is clear that steady decrease in tensile strength was observed with increasing burial time as presented in Tables 1 and 2. The tables show that there is increase in degradation rate of binary $\mathrm{PP} /$ starch blends with increasing starch content which resulted in the decrease of tensile strength for both compatibilized and uncompatibilized blends. At the end of 90 days, the percent loss in tensile strength in the blends containing $80 \mathrm{wt} . \%, 70 \mathrm{wt} . \%$, $60 \mathrm{wt} . \%$, and $50 \mathrm{wt} . \% \mathrm{PP}$ with respect to unburied blends was found to be $29.43 \%, 31.16 \%, 30.14 \%$, and $40.66 \%$ for PP/PCS blends and $18.67 \%, 22.08 \%, 18.26 \%$, and $20.23 \%$ for PP/PCCS blends. However, the irregular decrease for PP/PCCS blends may be attributed to compatibilizing and processing effects. The observed loss in structural integrity of the blends in soil with increasing starch content may be linked as an evidence for reduction in molecular weight of starch due to fragmentation during its retrogradation. Again, starch grains on the blend sample before burial are expected to disappear 
as they are consumed by microorganisms and insects in the soil leaving a blend with a surface full of cavities. This results in deterioration and loss of mechanical properties, and the blend becomes fragile. Another possible reason is that plasticized starch contains glycerol which is very soluble in water and its leaching contributes to the loss in tensile strength. It is pertinent to state here that though starch is fully biodegradable, a time period greater than 90 days is required for total consumption since it is covered with PP matrix.

Generally the compatibilized blends showed a reduction in the percent decrease due to the addition of compatibilizer which led to the improved interfacial adhesion between the starch and the PP matrix thus reducing the rate of water diffusion into the blends necessary for degradation inside the blends.

\section{Conclusion}

From the present study, it is concluded that degradation affects the tensile properties of PP/CS blends. The results obtained from the tensile tests after exposure to soil burial test revealed that variation occurs in tensile strength, elongation at break, and Young's modulus with different levels of starch content in the blends. The results pointed out that the PP/PCCS blends showed higher tensile strength, elongation at break, and Young's modulus than PP/PCS blends due to enhanced interfacial adhesion between the PP matrix and CS. However, all the blends under study showed a reduction in the tensile properties with increase in starch content as well as burial time and progressed as the burial time increased. The study has indicated that blending PP with cassava starch has enhanced the biodegradability of PP mainly because of the increased polymer surface created after starch consumption by microorganisms.

\section{References}

[1] F. P. La Mantia, C. Scaffaro, and C. Bastioli, "Recycling of a starch-based biodegradable Polymer," Macromolecular Symposia, vol. 180, no. 1, pp. 133-140, 2002.

[2] V. T. Breslin, "Degradation of starch-plastic composites in a municipal solid waste landfill," Journal of Environmental Polymer Degradation, vol. 1, no. 2, pp. 127-141, 1993.

[3] W. Liu, Y.-J. Wang, and Z. Sun, "Effects of polyethylenegrafted maleic anhydride (PE-g-MA) on thermal properties, morphology, and tensile properties of low-density polyethylene (LDPE) and corn starch blends," Journal of Applied Polymer Science, vol. 88, no. 13, pp. 2904-2911, 2003.

[4] D. Bikiaris and C. Panayiotou, "LDPE/starch blends compatibilized with PE-g-MA copolymers," Journal of Applied Polymer Science, vol. 70, no. 8, pp. 1503-1521, 1998.

[5] D. Raghavan, "Characterization of biodegradable plastics," Polymer-Plastics Technology Engineering, vol. 34, no. 1, pp. 4163, 1995.

[6] R. L. Shogren, C. L. Swansin, and A. R. Thompson, "Extrudates of corn starch with urea and glycols: structure/mechanical property relations," Starch Starke, vol. 44, pp. 335-338, 1992.
[7] L. Averous, N. Fauconnier, L. Moro, and C. Fringant, "Blends of thermoplastic starch and polyesteramide: processing and properties," Journal of Applied Polymer Science, vol. 76, no. 7, pp. 1117$1128,2000$.

[8] N. St-Pierre, B. D. Favis, B. A. Ramsay, J. A. Ramsay, and H. Verhoogt, "Processing and characterization of thermoplastic starch/polyethylene blends," Polymer, vol. 38, no. 3, pp. 647-655.

[9] H. Ismail, A. R. Majid, and M. R. Taib, "Effects of soil burial on properties of LDPE/thermoplastic sago starch blends," Pertanika Journal of Science and Technology, vol. 19, no. 1, pp. 189-197, 2011.

[10] A. C. Albertsson and S. Karlsson, "Degradable polymers for the future," Acta Polymers, vol. 46, no. 2, pp. 114-123, 1995. 

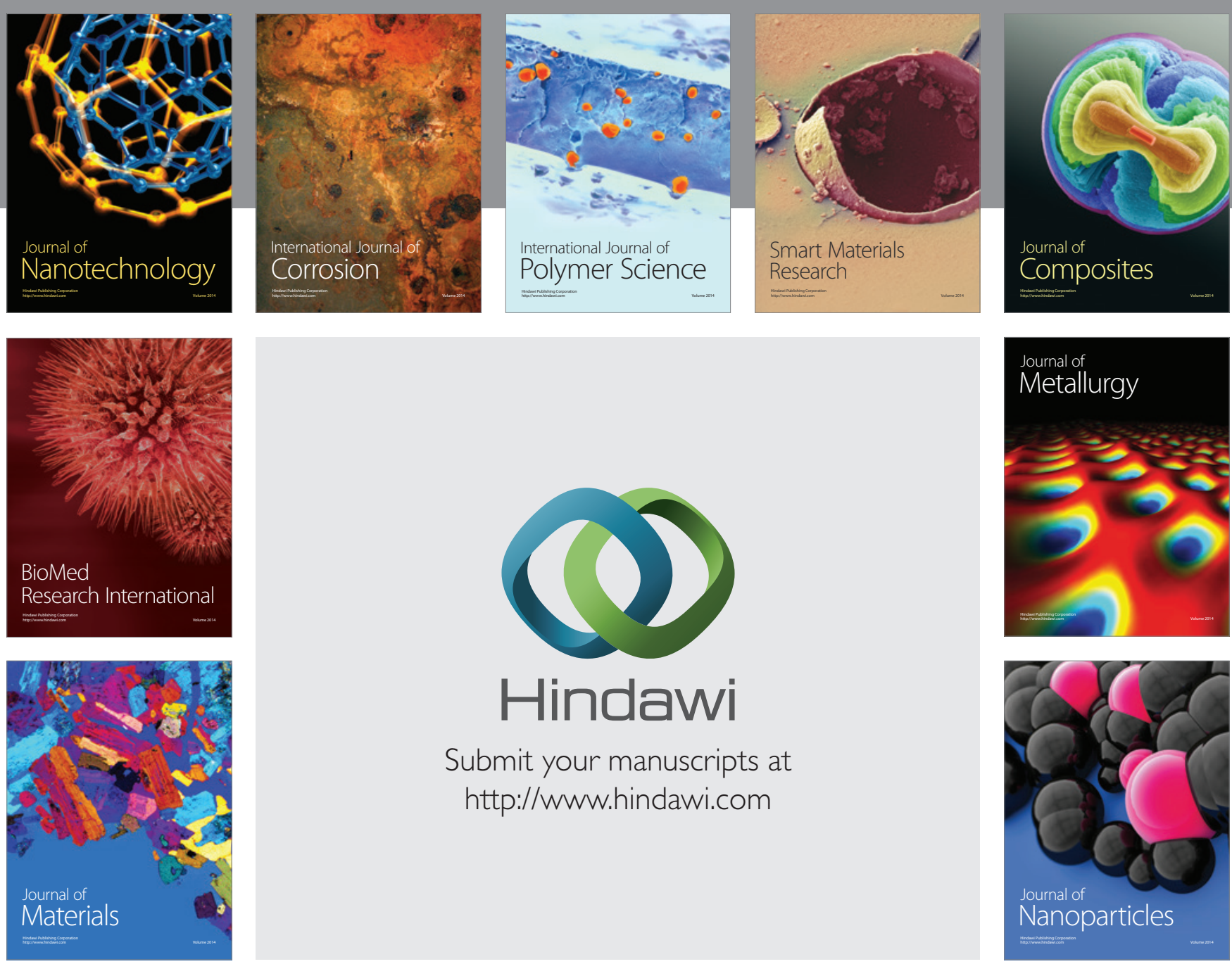

Submit your manuscripts at http://www.hindawi.com
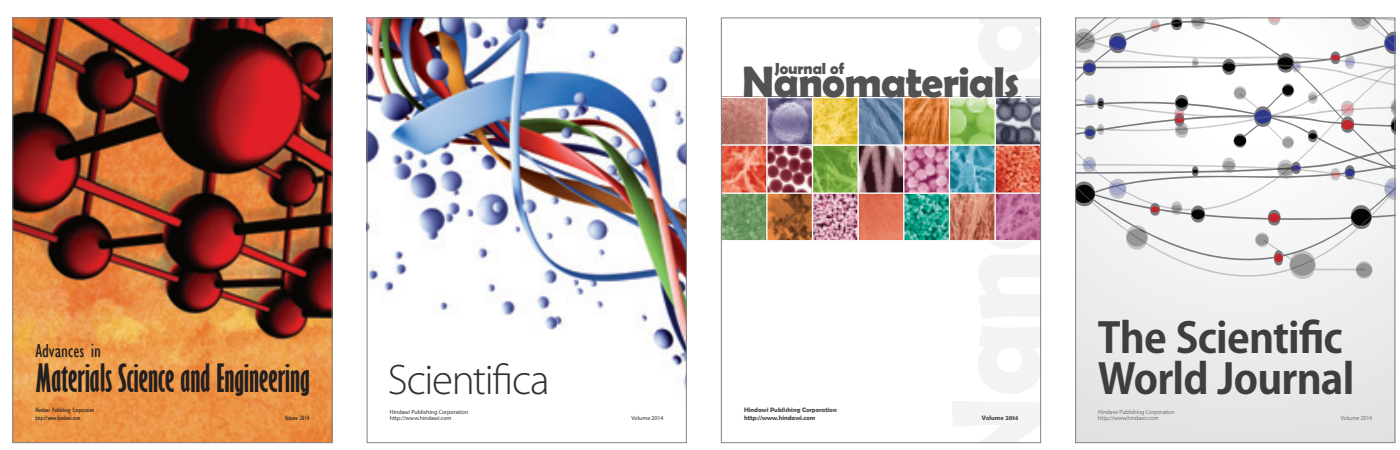

\section{The Scientific World Journal}
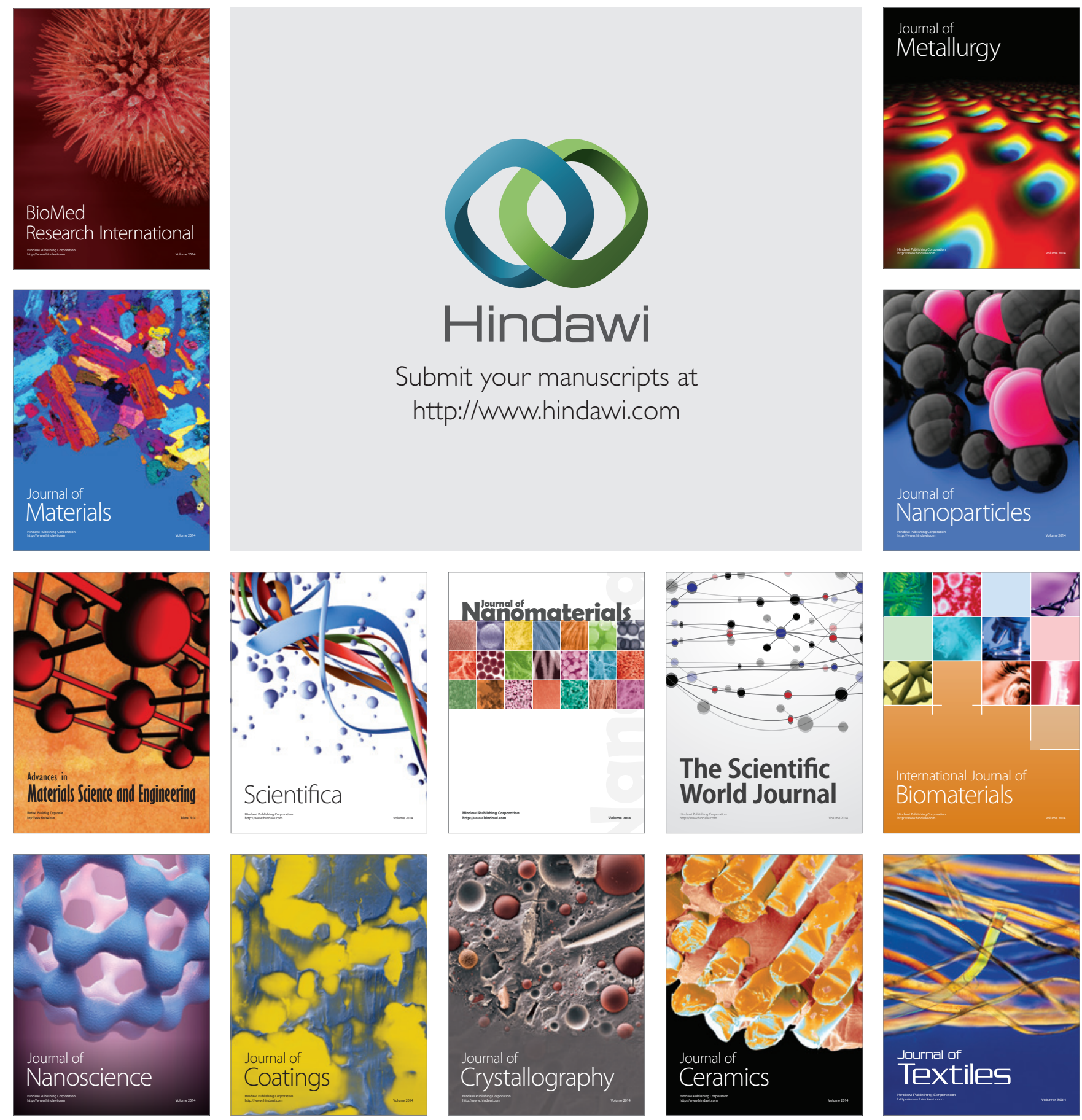